NASA/TM—2006-214264

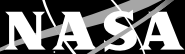

Liquid Hydrogen Sensor Considerations for Space Exploration

Matthew E. Moran

Glenn Research Center, Cleveland, Ohio 


\section{NASA STI Program . . . in Profile}

Since its founding, NASA has been dedicated to the advancement of aeronautics and space science. The NASA Scientific and Technical Information (STI) program plays a key part in helping NASA maintain this important role.

The NASA STI Program operates under the auspices of the Agency Chief Information Officer. It collects, organizes, provides for archiving, and disseminates NASA's STI. The NASA STI program provides access to the NASA Aeronautics and Space Database and its public interface, the NASA Technical Reports Server, thus providing one of the largest collections of aeronautical and space science STI in the world. Results are published in both non-NASA channels and by NASA in the NASA STI Report Series, which includes the following report types:

- TECHNICAL PUBLICATION. Reports of completed research or a major significant phase of research that present the results of NASA programs and include extensive data or theoretical analysis. Includes compilations of significant scientific and technical data and information deemed to be of continuing reference value. NASA counterpart of peer-reviewed formal professional papers but has less stringent limitations on manuscript length and extent of graphic presentations.

- TECHNICAL MEMORANDUM. Scientific and technical findings that are preliminary or of specialized interest, e.g., quick release reports, working papers, and bibliographies that contain minimal annotation. Does not contain extensive analysis.

- CONTRACTOR REPORT. Scientific and technical findings by NASA-sponsored contractors and grantees.
- CONFERENCE PUBLICATION. Collected papers from scientific and technical conferences, symposia, seminars, or other meetings sponsored or cosponsored by NASA.

- SPECIAL PUBLICATION. Scientific, technical, or historical information from NASA programs, projects, and missions, often concerned with subjects having substantial public interest.

- TECHNICAL TRANSLATION. Englishlanguage translations of foreign scientific and technical material pertinent to NASA's mission.

Specialized services also include creating custom thesauri, building customized databases, organizing and publishing research results.

For more information about the NASA STI program, see the following:

- Access the NASA STI program home page at http://www.sti.nasa.gov

- E-mail your question via the Internet to help@sti.nasa.gov

- Fax your question to the NASA STI Help Desk at 301-621-0134

- Telephone the NASA STI Help Desk at 301-621-0390

- Write to:

NASA STI Help Desk

NASA Center for AeroSpace Information 7121 Standard Drive Hanover, MD 21076-1320 
NASA/TM-2006-214264

.

(48.

.

\section{Liquid Hydrogen Sensor Considerations for Space Exploration}

Matthew E. Moran

Glenn Research Center, Cleveland, Ohio

Prepared for the

Sensors Applications Symposium 2006

sponsored by the Institute of Electrical and Electronics Engineers

Houston, Texas, February 7-9, 2006

National Aeronautics and

Space Administration

Glenn Research Center

Cleveland, Ohio 44135 
Level of Review: This material has been technically reviewed by technical management.

Available from

NASA Center for Aerospace Information

7121 Standard Drive

Hanover, MD 21076-1320
National Technical Information Service 5285 Port Royal Road Springfield, VA 22161

Available electronically at http://gltrs.grc.nasa.gov 


\title{
Liquid Hydrogen Sensor Considerations for Space Exploration
}

\author{
Matthew E. Moran \\ National Aeronautics and Space Administration \\ Glenn Research Center \\ Cleveland, Ohio 44135
}

\begin{abstract}
The on-orbit management of liquid hydrogen planned for the return to the moon will introduce new considerations not encountered in previous missions. This paper identifies critical liquid hydrogen sensing needs from the perspective of reliable on-orbit cryogenic fluid management, and contrasts the fundamental differences in fluid and thermodynamic behavior for ground-based versus on-orbit conditions. Opportunities for advanced sensor development and implementation are explored in the context of critical Exploration Architecture operations such as on-orbit storage, docking, and trans-lunar injection burn. Key sensing needs relative to these operations are also examined, including: liquid/vapor detection, thermodynamic condition monitoring, mass gauging, and leak detection. Finally, operational aspects of an integrated system health management approach are discussed to highlight the potential impact on mission success.
\end{abstract}

\section{Introduction}

The recent unveiling of NASA's Exploration Architecture reveals a scenario that will mark a first in space operations: the extended storage and handling of large quantities of liquid hydrogen on-orbit. The closest precedent has been much shorter coast periods of Centaur upper stages for some missions (e.g., $33 \mathrm{~min}$ for the Mars Reconnaissance Orbiter (ref. 1). The on-orbit management of liquid hydrogen planned for the return to the moon will introduce new and critical considerations not encountered in previous missions.

Figure 1 provides a conceptual operations timeline for the earth-to-orbit phase of the mission (refs. 2 and 3). First, the Cargo Launch Vehicle (CaLV) delivers the Lunar Surface Access Module (LSAM) and the Earth Departure Stage (EDS) to low earth orbit (LEO). The Crew Exploration Vehicle (CEV) is delivered to LEO next on a separate Crew Launch Vehicle (CLV). Finally, the CEV, LSAM, and EDS rendezvous on-orbit and begin the trans-lunar injection burn.

The elapsed time between the CaLV lift-off and the docking of the CEV, LSAM, and EDS could be from hours to days depending on a variety of factors including mission planning, pre-launch anomalies, and weather conditions. During this period the liquid hydrogen/liquid oxygen departure stage is subjected to a low-gravity orbital environment that poses unique challenges for liquid hydrogen system management.
Similar low-gravity cryogenic fluid management challenges result from the operational need for a fueled CEV/SM (service module) to remain at the International Space Station (ISS) for periods up to six months, with the capability to leave the ISS within minutes (ref. 4).

From a commercial space perspective, NASA Administrator Michael Griffin has consistently stated his interest in promoting private sector development of space transportation elements such as earth-orbiting fuel depots (ref. 5). These depots could replenish space vehicles bound to the moon or Mars with liquid hydrogen and other required propellants that typically make up half the weight of an earth-launched vehicle, thus substantially reducing launch costs. New liquid hydrogen sensor technologies will be necessary to enable orbital depots, and will also likely find application in groundbased systems supporting the emerging hydrogen economy infrastructure.

The objective of this paper is to identify critical liquid hydrogen sensing needs from the perspective of reliable on-orbit cryogenic fluid management. It is hoped that these identified needs will provide some insight into opportunities for advanced sensor development and implementation in support of the Exploration Architecture, as well as emerging commercial applications.

\section{Liquid Hydrogen System Issues}

All ground-based liquid hydrogen systems are predicated on decades of experience in a normal gravity environment, resulting in well known and manageable conditions:

\section{Liquid/Vapor Distribution}

Liquid settles at bottom of the tank, and the gaseous ullage collects at the top, resulting in a well defined flat interface. This predictable distribution of liquid and vapor permits critical operations such as liquid transfer from the tank bottom, gaseous venting from the tank top, active cooling by condensation of ullage vapor, and estimation of the liquid quantity via liquid level measurement.

\section{Thermal Stratification}

In general, the temperature distribution in both the liquid and vapor is horizontally stratified due to buoyancy forces. 


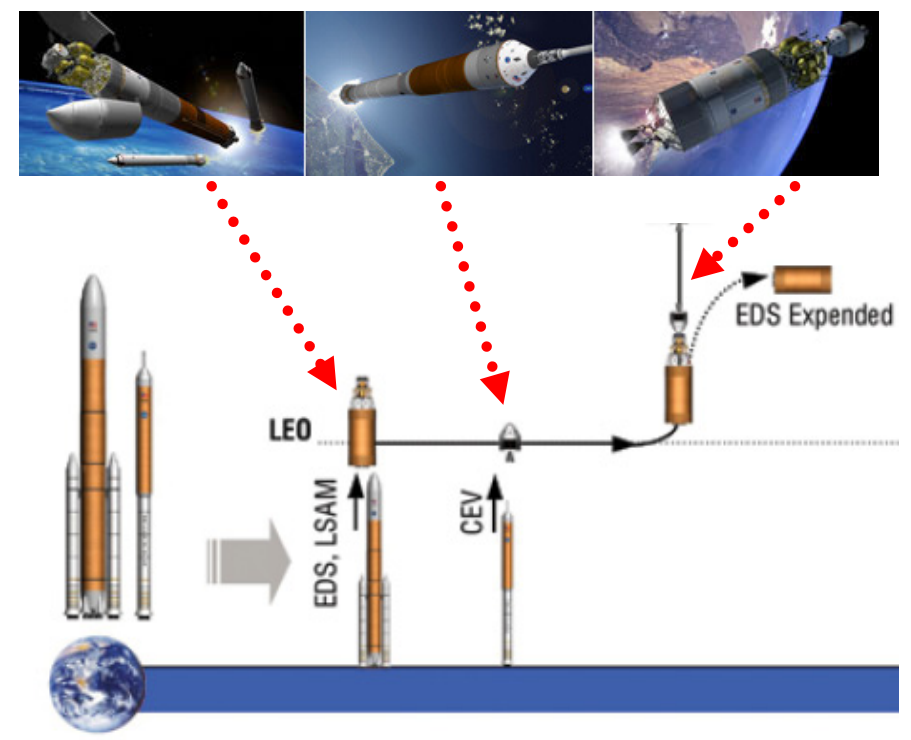

Figure 1.-Moon mission conceptual operations timeline (refs. 2 and 3).

The liquid-vapor interface is at saturation temperature dictated by the tank vapor pressure, with the ullage being increasingly superheated as a function of distance above the interface. If the tank pressure is maintained constant (e.g., by controlled venting) all of the liquid below the interface is also at saturation temperature. If the tank is being pressurized, the bulk of the liquid is subcooled at distances below the interface. This thermal stratification behavior allows reliable operations such as long term storage and pressurized liquid expulsion.

\section{Heat Transfer}

Heat leak from the environment can be quantified for a cryogenic tank as a function of environment conditions and fill level. The dependency on fill level is primarily due to two factors: higher heat leak paths from the tank penetrations (generally located at the top of the tank), and higher heat transfer rate at portions of the tank wall in contact with the liquid. Once quantified, the predictable heat leak performance of a liquid hydrogen tank allows reliable storage management and good estimation of the amount of hydrogen lost to boiloff over any period of time.

\section{Insulation Integrity}

Insulation performance can be monitored by measurement of the vacuum level in the insulated vacuum jacket of the tank. Any physical damage to the outer surface of the tank, or leakage from within the tank, will be immediately evident from a rise in vacuum jacket pressure. The timely indication of degraded insulation performance is critical to minimizing loss of hydrogen from the tank.

\section{Leak detection}

Hydrogen leaks will quickly vaporize, warm, diffuse, and rise in an air environment due to buoyancy effects. This behavior allows placement of a minimum number of leak detectors in key locations. Reliable detection of hydrogen leaks is critical to both operational safety, and maintenance of hydrogen quantity.

Most of these conditions are also relevant in the induced acceleration environment of a launch vehicle under thrust. On-orbit, however, none of the above conditions are valid. Instead, a new set of conditions exists that must be addressed by a combination of system design, operational procedures, and advanced sensors to insure mission success. Table 1 summarizes the difference in key conditions for ground-based versus on-orbit liquid hydrogen systems.

\section{TABLE 1.-COMPARISON OF GROUND AND ORBITAL LIQUID HYDROGEN SYSTEMS}

\begin{tabular}{|l|l|l|}
\hline \multicolumn{1}{|c|}{ Condition } & \multicolumn{1}{|c|}{ Ground-Based } & \multicolumn{1}{c|}{ On-Orbit } \\
\hline $\begin{array}{l}\text { Liquid/vapor } \\
\text { distribution }\end{array}$ & $\begin{array}{l}\text { Liquid at the bottom, } \\
\text { vapor at the top; flat } \\
\text { interface }\end{array}$ & $\begin{array}{l}\text { Various distributions } \\
\text { possible; interface(s) } \\
\text { defined by ullage bubble(s) }\end{array}$ \\
\hline $\begin{array}{l}\text { Thermal strati- } \\
\text { fication }\end{array}$ & $\begin{array}{l}\text { Horizontal stratification } \\
\text { due to buoyancy; super- } \\
\text { heated ullage region }\end{array}$ & $\begin{array}{l}\text { Stratification from walls } \\
\text { inward by conduction } \\
\text { only; saturated ullage }\end{array}$ \\
\hline Heat transfer & $\begin{array}{l}\text { Predictable heat leak as } \\
\text { a function of liquid level } \\
\text { and environment }\end{array}$ & $\begin{array}{l}\text { Heat leak dependent on } \\
\text { multiple variables; can } \\
\text { have liquid superheat }\end{array}$ \\
\hline $\begin{array}{l}\text { Insulation } \\
\text { integrity }\end{array}$ & $\begin{array}{l}\text { Can be monitored by } \\
\text { vacuum jacket press. }\end{array}$ & $\begin{array}{l}\text { Requires more complex } \\
\text { monitoring }\end{array}$ \\
\hline Leak detection & $\begin{array}{l}\text { Known leakage } \\
\text { behavior }\end{array}$ & $\begin{array}{l}\text { Complex leak paths and } \\
\text { plume characteristics }\end{array}$ \\
\hline
\end{tabular}

\section{Sensor Considerations}

Figure 2 illustrates some of the fundamental fluid behavior differences between a ground-based liquid hydrogen tank under normal gravity conditions and one in an orbital environment. These differences in fluid behavior, along with the other conditions summarized in Table I, point to the need for advanced sensing capabilities to insure reliable orbital operations.

Key sensing needs include: liquid/vapor detection, thermodynamic condition monitoring, mass gauging, and leak detection. In addition, several sensor system design drivers and desirable characteristics must be addressed such as: lightweight construction, low power draw, high reliability, multifunctional capabilities, and compatibility with integrated health system management configurations. 


\section{Liquid/Vapor Distribution}

Perhaps the most critical sensing need for extended management of liquid hydrogen on-orbit is the capability to detect the location of liquid and vapor within the tank. This capability is vital to key low-gravity operations such as venting for pressure relief and liquid transfer. For example, without reliable knowledge of the liquid/vapor distribution, significant quantities of liquid hydrogen can be inadvertently vented. Other concerns include injection of pressurant directly into the liquid resulting in insufficient pressurization; and/or ingestion of large quantities of vapor during engine firings. Any of these scenarios could potentially result in loss of mission.

Some generic sensing approaches to address this issue include: Combinations of operational procedures, liquid acquisition devices, and preferentially placed sensors; An array of point sensors of sufficient quantity and placement; Optical or other techniques that rely on differences in vapor and liquid refraction, transmission, reflection, etc.

\section{Thermodynamic Condition Monitoring}

Information on the thermodynamic condition of a cryogen, conventionally measured by temperature and pressure, is vital for extended on-orbit storage and cryogenic fluid management. Without detailed knowledge of thermodynamic conditions in all regions of a cryogenic tank, the behavior of the system under a variety of operations cannot be predicted. Some critical system behaviors and parameters related to thermodynamic conditions include: pressure control (ref. 7), ullage collapse (ref. 8), engine feed conditions, active cooling, and explosive boiling (ref. 9).

A single sensor (properly located) is generally sufficient to characterize the pressure for all cryogenic contents within a closed tank. However, multiple temperature sensing locations are needed due to the uncertain temperature distribution caused by the lack of buoyancy forces in low gravity. An array of temperature sensors, or innovative techniques for measurement of temperature dependent fluid properties, would allow inference of thermodynamic conditioning.

\section{Mass Gauging}

Accurate prediction of the quantity of liquid hydrogen remaining in a propellant tank is critical for mission operations. Traditional ground-based mass gauging techniques use point sensors or a capacitance probe to detect or infer the liquid level. Normal gravity insures that the interface defined by the liquid level separates the ullage gas in the upper region of the tank, and the liquid region below. The mass of liquid hydrogen in the tank can then be readily estimated with knowledge of the average liquid density and tank geometry.

In a low gravity environment, mass gauging techniques cannot assume a priori knowledge of the liquid-vapor

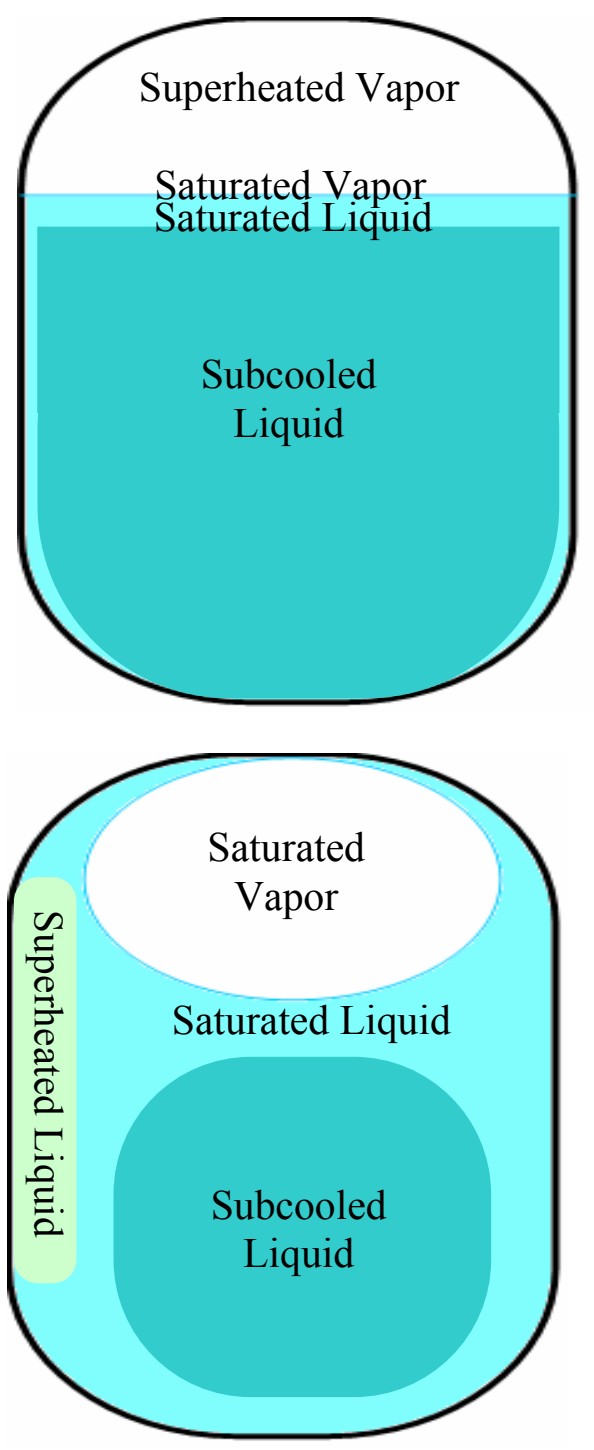

Figure 2.-Fluid behavior and thermodynamic conditions of ground-based (top) versus on-orbit (bottom) liquid hydrogen tanks.

distribution nor the geometry of the interface(s). Successful mass gauging methods must integrate data throughout the entire tank volume to arrive at an acceptable estimation of fill level. Proposed methods include: arrays of point sensors, optical/RF/microwave techniques, and acoustic/pressure wave methods.

\section{Leak Detection}

The potential for hydrogen leaks pose contamination, safety, and propellant loss risks. The characteristics of the plume formed by a hydrogen leak in space will vary based on a variety of vehicle, environmental, and leak source conditions. This variability complicates the detection of hydrogen 
leaks both on-orbit and in lunar transit. Possible methods to detect leaks may depend on optical/visual monitoring, point sensors in key locations, and/or internal tank monitoring (e.g., mass gauging).

\section{Summary Considerations}

Table 2 summarizes primary liquid hydrogen system parameters that need to be addressed. Also included are critical operations supported by each parameter, and some of the key issues that need to be resolved to implement a sensor based solution. Note that in general, it would be highly desirable to have more than one parameter measured or inferred by the same multifunctional sensor array (e.g., liquid/vapor detection, temperature, and mass gauging).

TABLE 2.-PRIMARY PARAMETERS, SUPPORTED OPERATIONS, AND KEY ISSUES

\begin{tabular}{|l|l|l|}
\hline \multicolumn{1}{|c|}{ Parameter } & \multicolumn{1}{c|}{ Operations } & \multicolumn{1}{c|}{ Issues } \\
\hline $\begin{array}{l}\text { Liquid/vapor } \\
\text { detection }\end{array}$ & $\begin{array}{l}\text { Venting, pressuriza- } \\
\text { tion, engine feed }\end{array}$ & $\begin{array}{l}\text { Spatial resolution, } \\
\text { response time }\end{array}$ \\
\hline $\begin{array}{l}\text { Thermodynamic } \\
\text { condition }\end{array}$ & $\begin{array}{l}\text { Storage, engine } \\
\text { feed }\end{array}$ & $\begin{array}{l}\text { Spatial resolution, } \\
\text { accuracy }\end{array}$ \\
\hline Mass gauging & Engine feed & Accuracy, uncertainty \\
\hline Leak detection & $\begin{array}{l}\text { Storage, vehicle } \\
\text { manuevers }\end{array}$ & $\begin{array}{l}\text { Source identification, } \\
\text { false negatives }\end{array}$ \\
\hline
\end{tabular}

Spatial resolution is a key issue for both liquid/vapor detection and thermodynamic condition monitoring. Because of the complex liquid and temperature distributions possible in a low-gravity environment, complete data throughout the tank internal volume is necessary. For liquid/vapor detection, fast response time (e.g., milliseconds) is also critical to capture fluid movements during periods of induced acceleration.

Since temperatures in the fluid will change in times scales of seconds to minutes, sensor accuracy is more critical than response time for thermodynamic condition monitoring. Changes in the liquid temperature of one degree Centigrade or less can have significant impact on the thermodynamic behavior of the system.

Key issues for mass gauging include both accuracy and uncertainty. An accurate estimate of liquid mass is critical to assessing whether sufficient propellant remains to support planned mission operations. Additionally, many currently proposed methods rely on fluid distribution assumptions that introduce potentially high uncertainty in the estimate of liquid mass.

For leak detection, the ability to pinpoint the source of the leak is critical in identifying appropriate corrective action. Also, the avoidance of "false negatives" (i.e., a leak is not detected by the sensor system) is paramount.

\section{Integrated System Health Management}

Key to maximizing the utility of any liquid hydrogen system sensor for space exploration is compatibility with an integrated system health management (ISHM) architecture. A liquid hydrogen system ISHM would enable automated realtime monitoring of critical system parameters, and ideally take corrective action when necessary to insure proper system operation. In the event that human intervention is necessary, the ISHM could also provide diagnostic data and procedural recommendations.

As a conceptual example of how a liquid hydrogen ISHM system might function, consider the Earth Departure Stage (EDS) of the Cargo Launch Vehicle (CaLV) as illustrated in figure 3 (ref. 10). Assume that the EDS liquid hydrogen tank is populated with an array of sensors that provide the necessary data to monitor liquid/vapor distribution, thermodynamic conditions, leakage, and liquid mass. Further assume that the EDS has been delivered to low earth orbit awaiting docking with the CEV. Below is a hypothetical mission scenario of how an ISHM system could operate under these conditions.

\section{On-Orbit Storage}

Orbital heat leak into the EDS hydrogen tank is absorbed primarily by the liquid, raising the average liquid temperature. Information on the thermal stratification (i.e., temperature distribution) of the liquid from the sensor array indicates that some of the liquid is subcooled relative to the tank pressure. Based on this data, the ISHM reduces tank pressure as needed

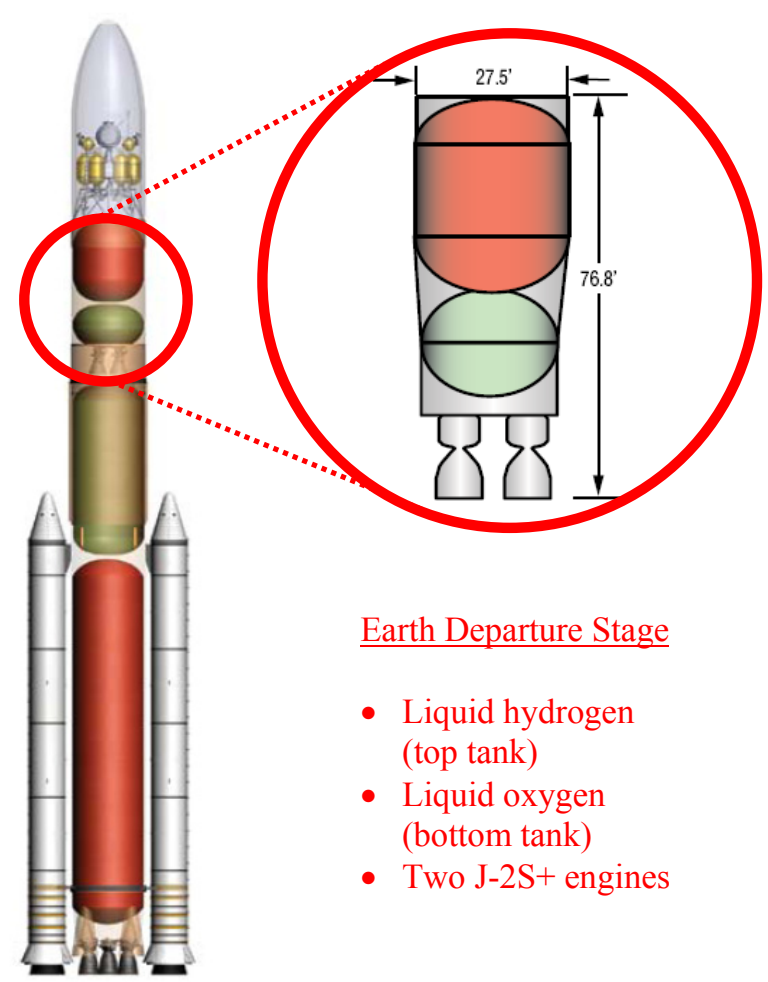

Figure 3.-Cargo launch vehicle general configuration and liquid hydrogen/liquid oxygen earth departure stage (ref. 10). 
by energizing a fluid mixer in the hydrogen tank to bring the contents into equilibrium.

Later in the mission, the sensor array detects superheated liquid on the sun-facing side of the tank. This condition can lead to explosive boiling and potential over-pressure of the tank. To mitigate this risk, the ISHM again energizes a mixer to eliminate the superheat.

Eventually, there is insufficient subcooling in the liquid to lower pressure by mixing. If a cryocooler has been integrated into the EDS hydrogen system, the ISHM begins active cooling of the tank and mixes the contents as necessary to lower pressure. If no active cooling capability exists, settling thrusters are fired by the ISHM to position the ullage gas over the vent port. Once the liquid/vapor detection function confirms the location of the ullage, the ISHM vents gas until the desired pressure is reached, and the thrusters are then deactivated.

\section{Docking}

Prior to docking with the CEV, the ISHM assesses the condition of the EDS liquid hydrogen system, predicts the effects the docking maneuver will have on the system, and prepares accordingly. Cryocooler and mixer operations are shut down at the earliest possible time to conserve power since the induced acceleration of the docking will provide mixing, and potential ullage positioning, for final pressure control adjustment.

An external leak detection sensor indicates a minute quantity of hydrogen is still coming from the tank following final venting for pressure control adjustment. The ISHM correlates this data with a colder than anticipated temperature down stream of the vent valve, and issues a command to cycle the valve. Once the ISHM has confirmed that this action has corrected the leakage problem, the docking sequence is initiated.

After docking, in preparation for pressurization of the tank for engine feed to begin trans-lunar injection, optimum tank pressure is reached by the ISHM based on all the parameter data supplied by the sensor array. Mass gauging confirms that propellant remains within acceptable margins to meet mission objectives.

\section{Trans-Lunar Injection}

As pressurization of the hydrogen tank begins prior to engine firing, the ISHM collects data on the internal tank conditions. The degree of subcooling of the bulk liquid is carefully monitored, and modified if necessary by mixing or other techniques to mitigate ullage collapse. Ullage collapse occurs when subcooled liquid comes in sudden contact with the liquid-vapor interface causing a rapid pressure drop to the saturation pressure value corresponding to the liquid temperature. During pressurized or pressure assisted expulsion, ullage collapse can cause disruption of propellant flow to the engines.

As the engines are fired, the temperature of the liquid leaving the hydrogen tank is monitored to insure the inlet temperature to the engines is within design range. The ISHM also senses temperatures throughout the bulk liquid (i.e., detailed temperature distribution) and takes any preemptive action necessary to insure the outlet temperature remains acceptable throughout the expulsion process. The mass gauging function insures that propellant usage is following the mission profile, otherwise the ISHM takes action to either correct the situation or provide critical data for human intervention decisions.

\section{Concluding Remarks}

The need for new sensor systems to enable cryogenic fluid management for the NASA's Exploration Architecture has been advocated, with particular emphasis on the orbital issues associated with the EDS liquid hydrogen tank. Sensor systems used for ground-based liquid hydrogen tanks are inadequate for extended low gravity cryogen management due to the fundamental differences in fluid and thermodynamic behavior.

Key required capabilities include: liquid/vapor detection, thermodynamic condition monitoring, fill level/mass gauging, and leak detection. Furthermore, the integration of these capabilities into an Integrated Health Management System can significantly reduce risk and increase the likelihood of mission success during critical operations such as on-orbit storage, docking, and trans-lunar injection.

A final issue for consideration are the trade-offs associated with alternative solutions that are not sensor-based. From a system integration standpoint, a new sensor system must demonstrate significant advantages over other design and operational approaches in order to be selected for implementation. Table 3 summarizes potential alternative methods for addressing the key on-orbit liquid hydrogen management issues raised in this paper, along with advantages and disadvantages of each approach. It is likely that an optimum solution will incorporate a hybrid approach that leverages the inherent advantages of integrated sensors, overall system design, and modified operational scenarios.

TABLE 3.-ALTERNATIVES TO SENSOR-BASED SOLUTIONS

\begin{tabular}{|l|l|l|l|}
\hline \multicolumn{1}{|c|}{ Issue } & \multicolumn{1}{|c|}{ Alternatives } & \multicolumn{1}{|c|}{ Advantages } & \multicolumn{1}{c|}{ Disadvantages } \\
\hline $\begin{array}{l}\text { Liquid/vapor } \\
\text { distribution }\end{array}$ & $\begin{array}{l}\text { Extensive use of } \\
\text { settling thrusters }\end{array}$ & $\begin{array}{l}\text { Predictable } \\
\text { liquid/vapor } \\
\text { distribution }\end{array}$ & $\begin{array}{l}\text { Increased pro- } \\
\text { pellant mass for } \\
\text { thrusters }\end{array}$ \\
\hline $\begin{array}{l}\text { Thermodyna- } \\
\text { mic conditions }\end{array}$ & $\begin{array}{l}\text { Extensive use of } \\
\text { mixer and/or } \\
\text { fluid circulation }\end{array}$ & $\begin{array}{l}\text { Maintains } \\
\text { equilibrium } \\
\text { conditions } \\
\text { throughout } \\
\text { the tank }\end{array}$ & $\begin{array}{l}\text { Increased } \\
\text { power, mass, } \\
\text { and complexity }\end{array}$ \\
\hline Mass gauging & $\begin{array}{l}\text { Active cooling; } \\
\text { no venting }\end{array}$ & $\begin{array}{l}\text { Constant mass } \\
\text { until engine } \\
\text { fire }\end{array}$ & $\begin{array}{l}\text { Power and mass } \\
\text { req's; no real- } \\
\text { time fuel gauge }\end{array}$ \\
\hline Leak detection & $\begin{array}{l}\text { Monitor static } \\
\text { tank pressure }\end{array}$ & $\begin{array}{l}\text { Simple imple- } \\
\text { mentation }\end{array}$ & $\begin{array}{l}\text { Some leaks may } \\
\text { go undetected }\end{array}$ \\
\hline Issue & Alternatives & Advantages & Disadvantages \\
\hline
\end{tabular}




\section{References}

1. "Mars Reconnaissance Orbiter: Stage II Centaur Upper Stage Booster," Jet Propulsion Laboratory, October 4, 2005.

2. "How We'll Get Back to the Moon," National Aeronautics and Space Administration, November 22, 2005.

3. "NASA's Exploration Systems Architecture Study: Final Report," NASA/TM-2005-214062, Nov., 2005, p. 7.

4. Ibid., p. 630.

5. "Call for Space Commercialization," Associated Press, League City, TX, November 16, 2005.

6. "NASA Wants Private Sector Help for Space," Reuters, Cape Canaveral, FL, November 16, 2005.
7. Lin, et al., "Pressure Control Analysis of Cryogenic Storage Systems," Journal of Propulsion and Power, Vol. 20, No. 3, May-June 2004.

8. Moran, et al., "Experimental Results of Hydrogen Slosh in a 62 Cubic Foot (1750 Liter) Tank," 30th Joint Propulsion Conference, June, 1994.

9. Hasan, et al., "Tank Pressure Control Experiment: Thermal Phenomena in Microgravity," NASA TP-3564, March, 1996.

10. "NASA's Exploration Systems Architecture Study: Final Report," NASA/TM-2005-214062, Nov. 2005, pp. 426-432. 


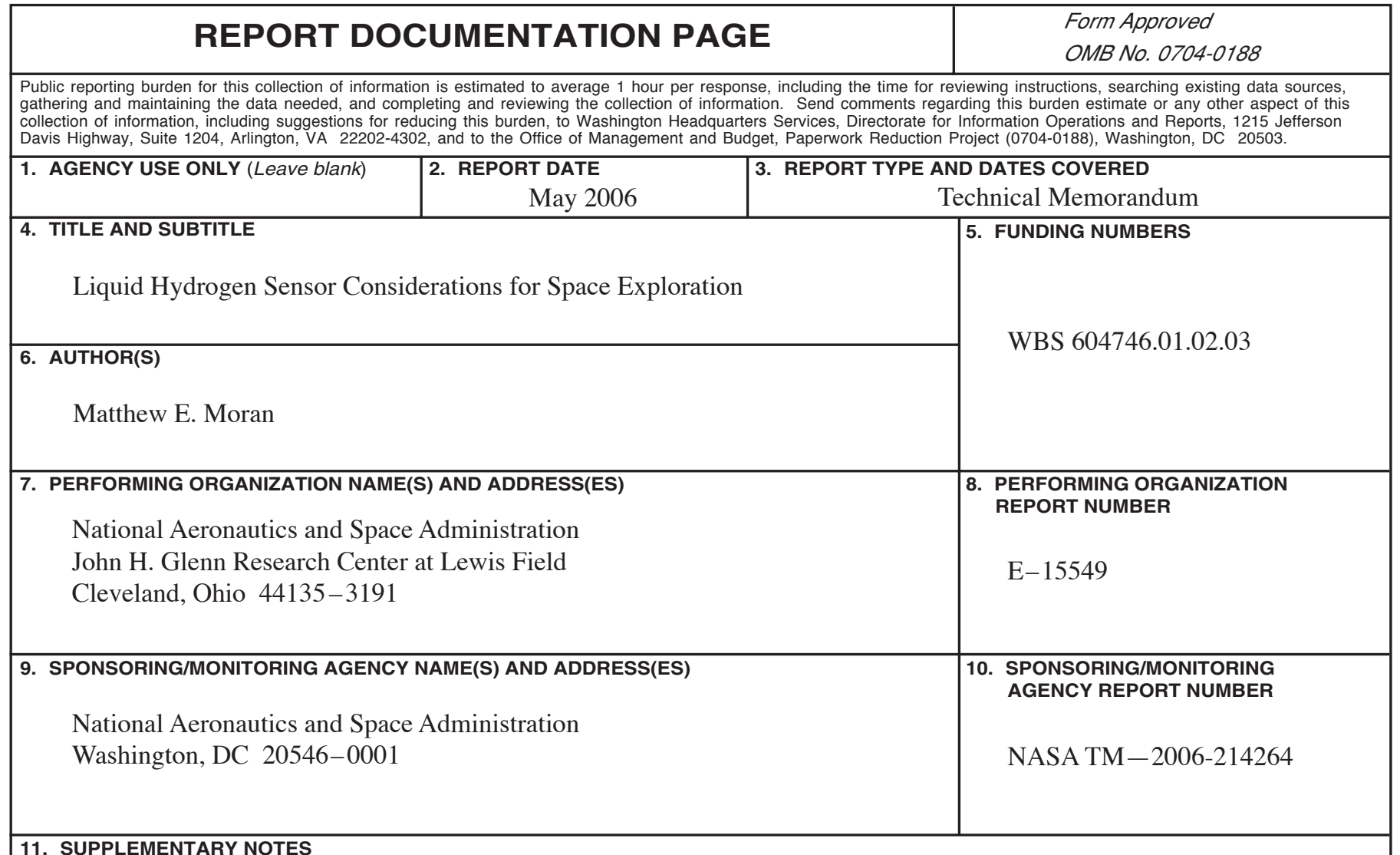

\section{SUPPLEMENTARY NOTES}

Prepared for the Sensors Applications Symposium 2006, sponsored by the Institute of Electrical and Electronics Engineers, Houston, Texas, February 7-9, 2006. Responsible person, Matthew E. Moran, organization code RPY, 216-433-8324.

\begin{tabular}{|l|l}
\hline 12a. DISTRIBUTION/AVAILABILITY STATEMENT & 12b. DISTRIBUTION CODE \\
Unclassified - Unlimited & \\
Subject Category: 20 & \\
Available electronically at http://gltrs.grc.nasa.gov & \\
This publication is available from the NASA Center for AeroSpace Information, 301-621-0390. &
\end{tabular}

13. ABSTRACT (Maximum 200 words)

The on-orbit management of liquid hydrogen planned for the return to the moon will introduce new considerations not encountered in previous missions. This paper identifies critical liquid hydrogen sensing needs from the perspective of reliable on-orbit cryogenic fluid management, and contrasts the fundamental differences in fluid and thermodynamic behavior for ground-based versus on-orbit conditions. Opportunities for advanced sensor development and implementation are explored in the context of critical Exploration Architecture operations such as on-orbit storage, docking, and trans-lunar injection burn. Key sensing needs relative to these operations are also examined, including: liquid/vapor detection, thermodynamic condition monitoring, mass gauging, and leak detection. Finally, operational aspects of an integrated system health management approach are discussed to highlight the potential impact on mission success.

\begin{tabular}{|c|c|c|c|}
\hline \multicolumn{3}{|l|}{ 14. SUBJECT TERMS } & 15. NUMBER OF PAGES \\
\hline \multicolumn{3}{|c|}{ Sensors; Hydrogen; Cryogenics; Propellants; Propulsion; Space Exploration; Low gravity } & 12 \\
\hline
\end{tabular}



